\title{
REOSSEOINTEGRATION OF BONE DEFECT SURROUNDING DENTAL IMPLANT ASSOCIATED WITH PERIIMPLANTITIS USING NANOBONE WITH OR WITHOUT SIMVASTATIN: A SIX MONTH RANDOMISED CONTROLLED CLINICAL TRIAL
}

\author{
Omar Hassan Soliman*
}

\begin{abstract}
Objectives: The aim of the study was evaluating the effect of adding simvastatin to synthetic bone substitute on the regenerative surgical treatment of bone defects associated with periimplantitis in a six months randomized controlled clinical trial.

Material \& Methods: 30 patients diagnosed with periimplantitis divided in two groups, group I treated by using synthetic bone substitute (Nanobone), group II treated by using Nanobone with simvastatin. Clinical evaluation was the measurements for probing pocket depth (PPD), clinical attachment level (CAL), plaque index (PI), modified sulcus bleeding index (mSBI) and mucosal recession. Radiographic bone fill was evaluated at baseline and after six months.
\end{abstract}

Results: The results for both treatment groups showed significant reductions obtained in the mean PPD, CAL and mSBI at six months postoperatively when compared to baseline values, on the other-side no statistically significant difference was observed for the mean PI and MR. The mean of bon fill in group II was better than that of group I and this results was statistically significant $(\mathrm{P}<0.05)$.

Conclusions: The two regenerative approaches produced significant improvements in both clinical and radiographic assessments, but adding simvastatin to Nanobone produce better results in terms of bone fill.

KEYWORDS: Nanobone, simvastatin, periimplantitis, surgical treatment.

\section{INTRODUCTION}

Periimplantitis is pathological disease characterised by irreversible bone loss surrounding dental implant, bleeding on probing (BoP), suppuration with or without concomitant increasing of periimplant pocket ${ }^{[1]}$. Recent systematic review showed $22 \%$ prevalence rate of periimplantitis ${ }^{[2]}$. Periodontitis and periimplantitis have a similar pathogenesis, this advocate similar management

\footnotetext{
* Lecturer of Oral Medicine , Periodontoloy and Oral Diagnosis، Faculty of Dentistry, South Valley University
} 
approaches ${ }^{[3,4]}$, but inflammatory infiltration in the apical extension is more pronounced in periimplantitis than in periodontitis, suggesting that periimplantitis progress faster than periodontitis ${ }^{[4,5]}$. The main goals of periimplantitis management are preserving the implant supporting tissue by the decontamination of exposed implant surfaces to inflammation resolution achievement ${ }^{[6]}$. Nonsurgical treatment has limited effect for moderate and sever periimplantitis, therefore surgical access required to improve cleans-ability of the implant surface and periimplant bone defect reconstruction ${ }^{[7]}$. There are many treatment protocols documented for achieving variable success ${ }^{[8-11]}$.

Regenerative surgical treatment of periimplantitis result in probing pocket depth reduction and bone defect fill ${ }^{[12-14]}$.

Nanotechnology used in periodontal tissue regeneration, there are several studies demonstrated the significance effect of nanoscale geometry and topography on the cell differentiation and regeneration $^{[15]}$. Nanobone (Artoss co, Germany) consisted of synthetic nano crystalline hydroxyapatite and silica fabricated in a sol/gel process. Based on the more recent results, Nanobone increase osteoblasts proliferation better than DBBM ${ }^{[16-18]}$ study showed that the inflammatory reaction is less in nano bone graft than betatricalcium phosphates graft [20,21]. Studies showed that, Nanobone is reliable and dimensionally stable bone graft ${ }^{[23-25]}$.

Statins are a drug used for the treatment of hypercholestrolemia by inhibiting of 3 hydroxy 3 methylglutaryl coenzyme A reductase and convert it to mevalonate and the end results is decreasing hepatic synthesis of cholesterol ${ }^{[26]}$. Statin derivate mevalonate and suppress the expression of the receptor for activation of nuclear factor kappa $\mathrm{B}$ ligand and activation of nuclear factor kappa B which inhibits osteoclast differentiations and induces osteoclast apoptosis ${ }^{[27,28]}$ studies showed that using of statins give rise to the so called pleiotropic effects by increasing the expression of bone morphogenetic proteins which stimulate the differentiation of osteoblast and increase its activity. Studies concluded that statin have an anabolic effect on bone ${ }^{[29]}$. Animal studies showedthat when statin applied locally give good bone regeneration ${ }^{[30-32]}$ and enhance new bone formation and bone to implant contact ${ }^{[33]}$.

To the best of author knowledge, the reported studies for using simvastatin to enhance the performance of osteoconductive bone substitute is limited. Therefore the aim of the presented study was to evaluate clinically and radiographically the effect of adding simvastatin to Nanobone on regenerative surgical treatment of periimplantitis during six months follow up.

\section{PATIENTS AND METHODS}

\section{Study design}

The study design was prospective, single centre, parallel randomized group and six months clinical trial. The study done to evaluate the effect of bone substitute;NanoBone (Artoss GmbH, Rostock, Germany) (group 1, control group) compared to the same bone substitute with simvastatin (Corvast $80 \mathrm{mg}$, Egyphar, Egypt) (group 2, test group) for RST of periimplantitis. 30 patients diagnosed with periimplantitis and indicated for regenerative surgical treatment for at least one periimplant bone defect selected (the most severe) and only one implant per the patient evaluated.

Periimplantitis diagnosed according to the criteria reported by the 8th European workshop on periodontology ${ }^{[34]}$, at lease $2 \mathrm{~mm}$ or more marginal bone loss is present based on the baseline periapical $\mathrm{x}$ ray after the delivery of final restoration and bleeding on probing and suppuration with or without increasing of the periimplant pocket depth. 


\section{Inclusion criteria}

Patient age $>18$ years, have bone defect $>3 \mathrm{~mm}$ to at least one implant, periimplant pocket depth $>$ $5 \mathrm{~mm}$ with bleeding on probing and suppuration and more than $2 \mathrm{~mm}$ keratinized attached mucosa present. The implant system is Impla (Scheutz dental group, Germany).

\section{Exclusion criteria}

History of serious systemic disease, implants which augmented with bone graft, implant previously treated from periimplantitis and mobile implant.

\section{Surgical procedure}

Before surgical treatment, nonsurgical treatment was done to all patients by full mouth mechanical debridement and oral hygiene instructions then clinical reexamination performed one months, patient plaque score and bleeding score must below $20 \%$.

Local anaesthesia administrated then full thickness mucoperiosteal flap done by sulcular incision around the neck of the implants (Impla implant system, Scheutz dental group) and exposed distally and mesially to expose labial and lingual/ palatal aspects of implant. Debridement of bone defect on the surfaces of implant using titanium curettes. For group I, bone defect filled with Nanobone and for group II bone defect filled with Nanobone and simvastatin. Simvastatin tablet crushed and mixed with normal saline. The flaps repositioned and sutured. All surgical procedures performed by one experienced periodontist.

Antibiotics (Augmentin 1gram 1X2) and Metronidazol (Amrizol 500 1X3) prescribed to
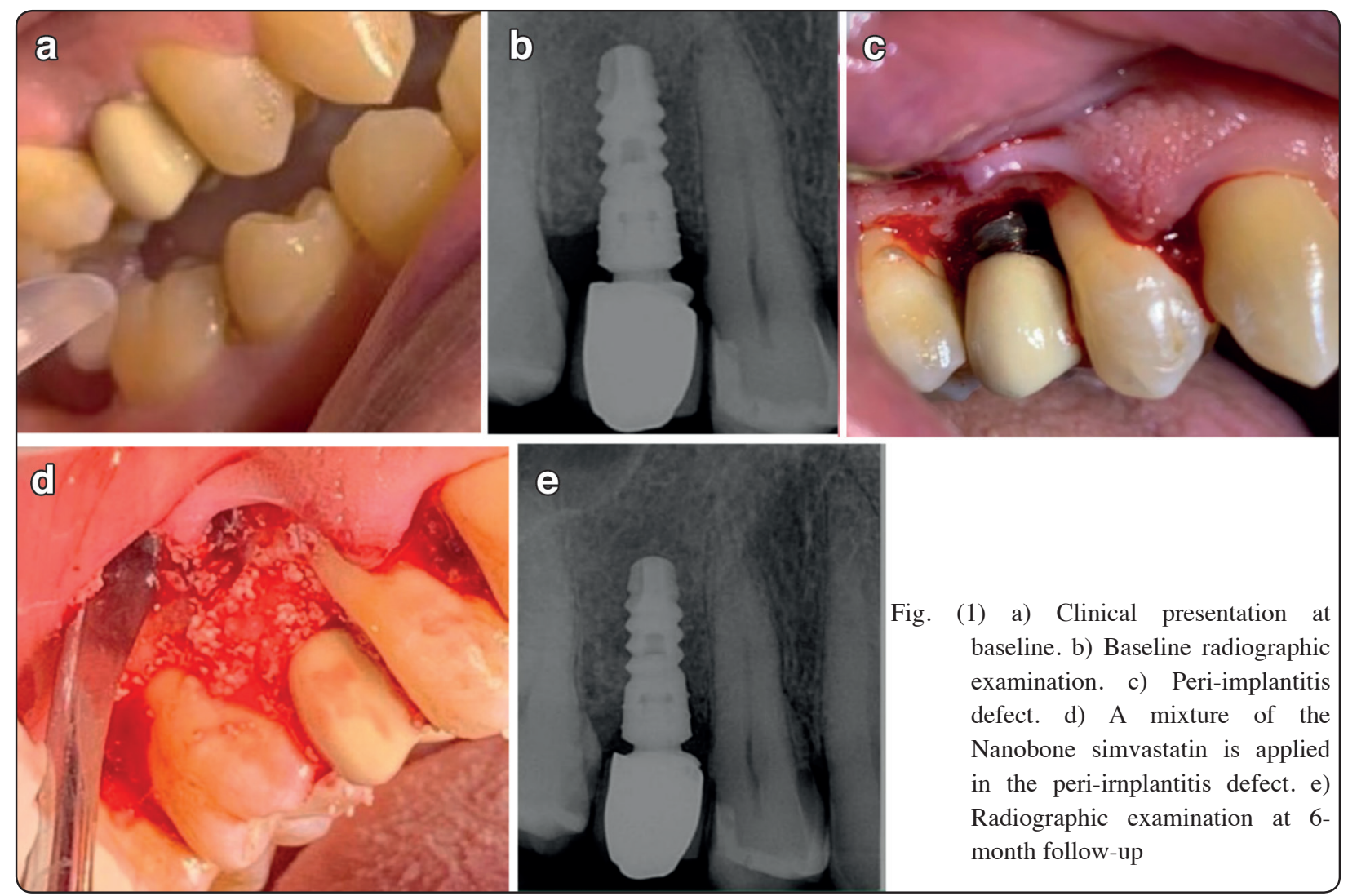

Fig. (1) a) Clinical presentation at baseline. b) Baseline radiographic examination. c) Peri-implantitis defect. d) A mixture of the Nanobone simvastatin is applied in the peri-irnplantitis defect. e) Radiographic examination at 6month follow-up 


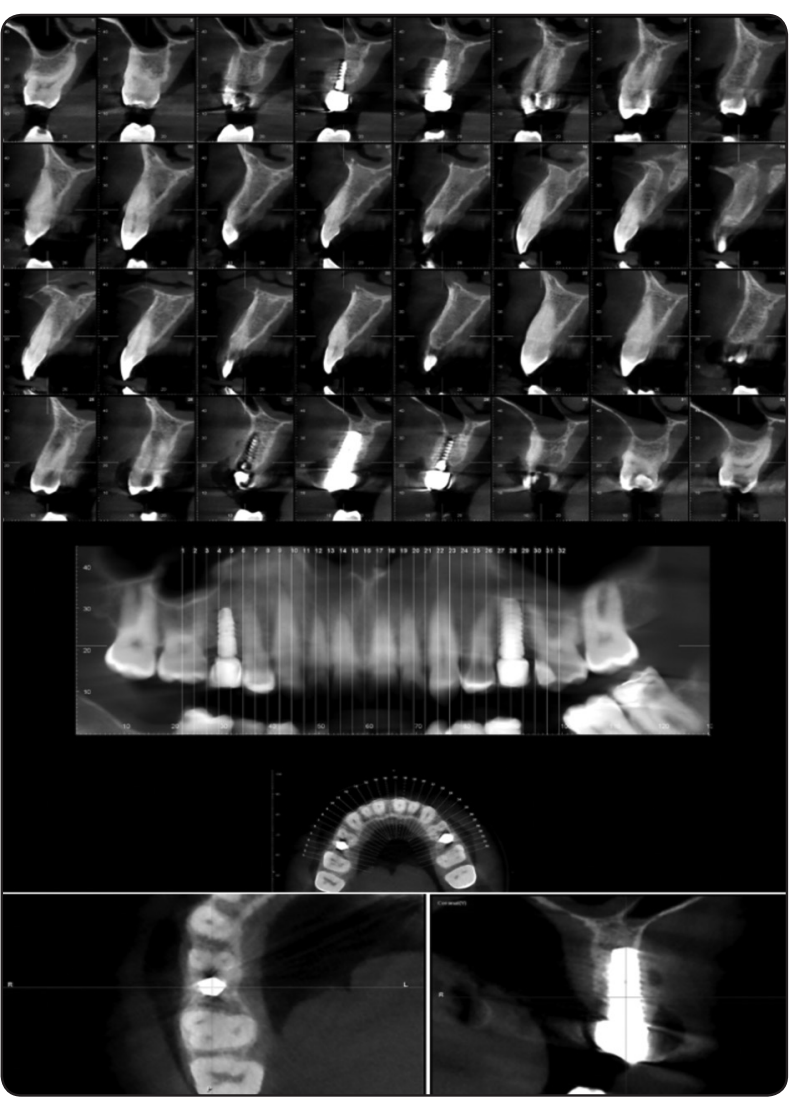

Fig. (2): Photo showing preoperative CBCT.

the patients for seven days, starting one day before the operation. Analgesic (Ibuprofen $400 \mathrm{mg}$ 1X2) prescribed for three days and $0.12 \%$ chlorhexidine digluconate mouthwash twice daily for two weeks. Instruction for the patient to not brush the surgical sites for two weeks and sutures removed two weeks after surgery. At a time interval of 1,3 , and 6 months supragingival mechanical debridement has been done and reinforcement of oral hygiene measurements to the patients.

\section{Clinical measurements}

Usingm flexible plastic probe all clinical measurements recorded before and six month after the surgery. Measurements recorded at six aspects per implant. Single examiner who is blinded to the treatment assignment were responsible for evaluating the clinical parameters:
1. Plaque index (PI) marked from 0 to 3 using Loe and Silness plaque index ${ }^{[35]}$. Grade I: plaque found on the implant surface after scratching gently by probe tip. Grade II: Plaque seen by naked eye and Grade III: Large amount of plaque seen.

2. Bleeding on probing $(\mathrm{BoP})$ recorded according to modified sulcus bleeding index (mSBI) as described by Mombelli ${ }^{[36]}$. Score 0: no bleeding, score I: isolated bleeding spots, score II: blood from confluent red line and score III: profuse blood.

3. Periimplant pocket depth recorded as the distance from the gingival margin to the base of the deepest periimplant pocket.

4. Mucosal recession measured as the distance from the mucosal margin and implant abutment interface.

5. Clinical attachment level defined as periimplant pocket depth plus mucosal recession.

\section{Radiographic measurements}

Using standardized long cone paralleling technique with individualised film holder introral periapical $\mathrm{x}$ ray films taken for involved implant. Marginal bone level evaluated by using computer assisted image analysis, author measure the distance from the abutment implant junction to bone level (bone implant contact point) and mean bone level calculated for each implant at baseline and six months postoperative. All radiological assessments performed by one investigator.

\section{RESULTS}

The study done in the clinic of periodontology department, faculty of dentistry, South Vally university. 30 patients diagnosed as periimplantitis completed the study (Table 1). Male to female ratio 2:1 and mean patients age 45.5. Bleeding and plaque scores for full mouth were less than $20 \%$ to all patients. 
At the baseline, clinical characteristics of the implants with periimplantitis were comparable in group I and II regarding to overall plaque and bleeding scores for all patients (Table 1).

TABLE (1) Baseline data of the studied groups.

\begin{tabular}{|l|l|l|}
\hline Parameters & Group I & Group II \\
\hline Age [mean \pm SD (years)] & $47( \pm 7)$ & $43( \pm 13)$ \\
\hline Gender n (\%) & & \\
Female & 6 & 4 \\
Male & 9 & 11 \\
\hline Tooth (n) & & \\
Central Incisor & 1 & 0 \\
Lateral Incisor & 2 & 3 \\
Canine & 0 & 1 \\
First premolar & 7 & 5 \\
Second premolar & 5 & 6 \\
\hline FMBS (\%) & $16 \pm 1.68$ & $14.2 \pm 2.71$ \\
\hline FMPS (\%) & $15.1 \pm 0.88$ & $17.3 \pm 1.01$ \\
\hline Loading time & $4.72 \pm 1.01$ & $5.21 \pm 1.48$ \\
\hline
\end{tabular}

No significant intergroup differences were observed at baseline (Mann-whitneyUtest, $p>0.05$ ). FMBS (full mouth bleeding score), FMPS (full-mouth plaque score).

At six month after surgery: Plaque index shoed no significant change $(\mathrm{P}>0.05)$ to the baseline (Group I from $0.86 \pm 0.58$ to $0.45 \pm 0.76$ and Group II from $0.76 \pm 0.78$ to $0.77 \pm 0.55$ ). Bleeding index significantly $(\mathrm{P}<0.001)$ reduced from $1.98 \pm 0.80$ to $0.79 \pm 0.73$ in group I and from $1.87 \pm 0.79$ to $1.02 \pm 0.07$ in group II. Intragroup comparisons significant reduction in periimplant pocket depth and improvement in clinical attachment level were detected in both groups $(\mathrm{P}<0.001)$. The mean PPD at baseline was $6.20 \pm 0.97 \mathrm{~mm}$ for group I and was $6.46 \pm 1.02 \mathrm{~mm}$ for group II. These values significantly reduced to $2.73 \pm 0.77 \mathrm{~mm}$ and $2.80 \pm$ $0.75 \mathrm{~mm}$ at six months after surgery. No statistically significant difference was found regarding to mucosal recession (Table 2).

In both groups the periimplantitis were moderate, for group I the bone loss significantly reduced from
$4.05 \pm 1.04 \mathrm{~mm}$ before treatment to $2.57 \pm 1.45 \mathrm{~mm}$ after treatment and for group II bone loss reduced from $3.86 \pm 1.00$ to $1.77 \pm 0.70 \mathrm{~mm}$. The difference between the two groups was statistically significant in favour for the test group (Table 2). No implant was lost.

TABLE (2) Descriptive statistics of the clinical and radiographic parameters at baseline and 6 months after treatment

\begin{tabular}{|c|c|c|c|c|}
\hline \multicolumn{2}{|c|}{ Parameters } & & & $\mathrm{P}$ value Baseline \\
\hline \multirow{3}{*}{$\bar{a}$} & Group I & $0.86 \pm 0.58$ & $0.67 \pm 0.45$ & $p>0.05$ \\
\hline & group II & $0.76 \pm 0.78$ & $0.77 \pm 0.55$ & $p>0.05$ \\
\hline & Pvalue & $0.214^{b}$ & $0.848^{\mathrm{b}}$ & \\
\hline \multirow{3}{*}{$\begin{array}{l}\overline{0} \\
\text { ह } \\
\end{array}$} & Group I & $1.98 \pm 0.80$ & $0.79 \pm 0.73$ & $<0.001^{\mathrm{a}}$ \\
\hline & Group II & $1.87 \pm 0.79$ & $1.02 \pm 0.07$ & $<0.001^{\mathrm{a}}$ \\
\hline & Pvalue & $0.681^{\mathrm{b}}$ & $0.866^{\mathrm{b}}$ & \\
\hline \multirow{3}{*}{ 立 } & Group I & $6.20 \pm 0.97$ & $2.73 \pm 0.77$ & $<0.001^{\mathrm{a}}$ \\
\hline & Group II & $6.46 \pm 1.02$ & $2.80 \pm 0.75$ & $<0.001^{\mathrm{a}}$ \\
\hline & Pvalue & $0.509^{b}$ & $0.818^{b}$ & \\
\hline \multirow{3}{*}{ ষ্ট } & Group I & $6.50 \pm 2.0$ & $3.17 \pm 1.01$ & $<0.001^{\mathrm{a}}$ \\
\hline & Group II & $6.96 \pm 1.91$ & $3.52 \pm 0.87$ & $<0.001^{\mathrm{a}}$ \\
\hline & Pvalue & $0.509^{b}$ & $0.718^{b}$ & \\
\hline \multirow{3}{*}{$\stackrel{\Omega}{\Sigma}$} & Group I & $0.3 \pm 1.1$ & $0.6 \pm 1.0$ & $p>0.05$ \\
\hline & Group II & $0.5 \pm 0.98$ & $0.7 \pm 0.68$ & $p>0.05$ \\
\hline & Pvalue & $0.507^{b}$ & $0.717^{b}$ & \\
\hline \multirow{3}{*}{ 咨 } & Group I & $4.05 \pm 1.04$ & $2.57 \pm 1.45$ & $0.037^{\mathrm{a}}$ \\
\hline & Group II & $3.86 \pm 1.00$ & $1.77 \pm 0.70$ & $0.036^{\mathrm{a}}$ \\
\hline & Pvalue & $0.091^{\mathrm{b}}$ & $0.017^{\mathrm{b}}$ & \\
\hline
\end{tabular}

PI, Plaque index; mSBI, mean sulcular bleeding index; PPD, Probing pocket depth; CAL, Clinical attachment level; MR, Mucosal recession; DF, Defect fill. $p<.05$ considered statistically significant., aWilcoxon Signed Rank Test, , bMann-Whitney U test. 


\section{DISCUSSION}

Non augmentative surgical modalities for treating periimplantitis reduce the inflammation amount in short term but in long term have limited effect. For complete regeneration of periimplantitis the regenerative tissue must have sufficient strength to sustain the mechanical forces and architectural properties, porous internal structure and a surface optimised for attachment, migration, proliferation and cell differentiation ${ }^{[37]}$.

This study reported on six months outcome for randomised controlled clinical trial on the surgical treatment of periimplantitis by regenerative surgical protocol utilising Nanobone graft with or without simvastatin. Study results showed that, the two treatment approaches have comparable short term results but combining simvastatin with Nanobone graft has a more positive impact on increasing the bone gain when compared with Nanobone alone. The proposed strict inclusion criteria, make all patient in the two groups homogeneous. $2 \mathrm{~mm}$ of keratinized attached gingiva should be present and no restorative problems diagnosed related to the implant. Studies showed that, the lack of an adequate keratinized attached gingiva is related to higher risk of periimplant inflammation and led to soft and hard tissue loss ${ }^{[38]}$.

In order to include a group of patients that was as homogeneous as possible, strict inclusion criteria were proposed. This study targeted patients diagnosed with moderate to severe periimplantitis (bone defect $\geq 3 \mathrm{~mm}$ ), this because it is difficult for complete resolving the periimplantitis in these patients with only non surgical debridement. In order to avoid the influence of host related factors, only one implant included even more implants were affected in the patient. The study of Persson et al 2001 concluded that the quality of titanium surface is decisive importance for both osseointegration and reosseointegration, so all included implants are of the same brand (Impla implant system, scheutz dental group) ${ }^{[38]}$.
Properimplantinstrumentationincludesremoving microbial deposits without altering the implant surfaces or adversely affecting biocompatibility. Implant surface scratches may affect the titanium oxide layer, reducing the corrosion resistant nature of a titanium implant. Implant surface become contaminated with trace elements from the scaler material that remains, which compromise the long term osseointegration of the implant. Study showed that, plastic and titanium scalers are all within safe limits for instrumenting on implant surface ${ }^{[39]}$, soin this study flexible plastic probe has been used for clinical measurementsof periimplant pocket depth and titanium scaler has been used for mechanical debridement of bone defect on the surfaces of implant.

Autologous bone has osteogenic, osteoinductive and osteoconductive properties, so considered the gold stander for regeneration and bone augmentation in oral and maxillofacial surgery, but its availability is limited and restricting factors must considered due to the need for second surgical site and donor site morbidity ${ }^{[40]}$.

Nanobone is fully synthetic bone graft, composed of nanohydroxyappatiete and a matrix of silica ge ${ }^{[41]}$. Nanobone is osteoconductive so it stabilize the blood clot, guide osteogenic cells to augmentation site and provide the surface for forming new bone ${ }^{[42]}$. Studies showed that, local delivery of the bioactive substances in a combination with osteoconductive bone graft could improve the treatment outcomes of periimplantitis. Statins have dual anabolic and antiresorptive effects on the bone, so considered an ideal antiosteoporotic drugs ${ }^{[42]}$. Local application of statins as adjuncts to SRP for periodontitis treatment recommended by recent systemic reviews and met-analysis based on low cost, lesser adverse effect on bacterial resistance ${ }^{[44]}$. Assessment of periimplant health is based on the clinical parameters (BoP \& PPD) and marginal periimplant bone level ${ }^{[45]}$. The presented study 
demonstrated high improvements regarding to PPD, BoP and CAL values at six months follow yp compared to the baseline in the two Groups. Study results showed that: the mean PPD reduction were relatively higher than the studies which used bone graft alone without biologically active materials ${ }^{[46-47]}$, reported statically significant comparable improvement in the terms of the mean CAL for the two groups $(p=0.001)$ and didn't report intragroup or intergroup differences in the mean MR.

Despite the usefulness of CBCT in the detection of periimplant bone defect, beam hardening artefacts from dental implant may affect its diagnostic performance. The higher resolution with 10 to 25 line pairs per $\mathrm{mm}(\mathrm{lp} / \mathrm{mm})$ for intraoral radiographs facilitates a higher accuracy in displaying details, while CBCT reveal a lower resolution with only 1 to $2 \mathrm{lp} / \mathrm{mm}$, and has a smaller distortion and magnification effects ${ }^{[48]}$. Studies reported that CBCT was less accurate for assessing periimplant bone loss than intraoral radiographs ${ }^{[49]}$. Results showed limitations of CBCT in accurately determining the bone levels of implants in the vertical as well as the horizontal dimensions ${ }^{[50]}$. This conducted with the preoperative radiological evaluation (CBCT and periapical $\mathrm{x}$ ray) for all patients in this study (Fig. 2). Stefane R et al. 2019 recommended long cone paralleling introral periapical $\mathrm{x}$ ray films to assess interproximal crestal bone changes around the implants ${ }^{[51]}$.So in this study standardized long cone paralleling technique with individualised film holder introral periapical $\mathrm{x}$ ray films has been used for the evaluation of the involved implant.

The results of this study showed that, the mean radiographic amount of bone fill in the test group was about $2.09 \pm 0.79 \mathrm{~mm}$, this mean defect bone fill of approximately $54 \%$, which higher than that observed in the control group in which the defect bone fill was $1.48 \pm 1.05$ (about $36.5 \%$ ), this beneficial effects of simvastatin attributed to their immunoreguratory effects on epithelial cells in addition to its dual anabolic and antiresorptive effects ${ }^{[47]}$, as well as it has antibacterial properties ${ }^{[48]}$. Clinical studies showed that simvastatin has pleiotropic effects on periodontitis patients, they expressed lower IL-1 levels on statin medication ${ }^{[49]}$, down-regulation of IL-1 $\beta$, myeloperoxidase levels, and higher anti-inflammatory IL-10 levels in gingival crevicular fluid compared to patients without statin treatment ${ }^{[50]}$.

In conclusion, this study suggested that, adjunctive use of simvastatin with Nanobone seems to br beneficial for regenerative surgical treatment of periimplantitis.

\section{REFERENCES}

1. Lang NP, Berglundh T (2011) Working Group 4 of Seventh European Workshop on Periodontology. Periimplant diseases: where are we now?-Consensus of the Seventh European Workshop on Periodontology. J Clin Periodontol. 38(Suppl 11):178-181.

2. Derks J, Tomasi C (2015) Peri-implant health and disease. A systematic review of current epidemiology. J Clin Periodontol. 42(suppl 16): S158-S171.

3. Heitz-Mayfield, L. J. A (2008) Peri-implant diseases: Diagnosis and risk indicators. Journal of Clinical Periodontology, 35(8), 292-304.

4. Heitz-Mayfield, L. J. A., \& Lang, N. P (2010) Comparative biology of chronic and aggressive periodontitis vs. periimplantitis. Periodontology 2000, 53(1), 167-181. https:// doi. org/10.1111/j.1600-0757.2010.00348.x

5. Carcuac, O., \& Berglundh, T (2014) Composition of human peri-implantitis and periodontitis lesions. Journal of Dental Research, 93(11), 1083-1088.

6. Esposito M, Grusovin MG, Worthington HV (2012) Interventions for replacing missing teeth: treatment of periimplantitis. The Cochrane Database Syst Rev.;1:Cd004970.

7. Figuero E, Graziani F, Sanz I, et al (2014) Management of peri-implant mucositis and peri-implantitis. Periodontol 2000.; 66:255-273.

8. Roos-Jansaker AM, Persson GR, Lindahl C, Renvert S(2014) Surgical treatment of peri-implantitis using a bone substitute with or without a resorbable membrane: a 5-year follow-up. J Clin Periodontol.;41: 1108-1114. 
9. Roccuzzo M, Pittoni D, Roccuzzo A, Charrier L, Dalmasso P (2017) Surgical treatment of peri-implantitis intrabony lesions by means of deproteinized bovine bone mineral with 10\% collagen: 10-year-results. Clin Oral Implants Res.;28:1577-1583.

10. Schwarz F, John G, Schmucker A, Sahm N, Becker J(2017) Combined surgical therapy of advanced peri-implantitis evaluating two methods of surface decontamination: a 7-year follow-up observation. J Clin Periodontol 2017.; 44:337-342.

11. Hallström H, Persson GR, Lindgren S, Renvert S(2017) Open flap debridement of peri-implantitis with or without adjunctive systemic antibiotics: a randomized clinical trial. J Clin Periodontol2017;44: 1285-1293.

12. Ramanauskaite A, Daugela P, Juodzbalys G (2016) Treatment of peri-implantitis: meta-analysis of findings in a systematic literature review and novel protocol proposal. Quintessence Int.;47: 379-393.

13. Daugela P, Cicciu M, Saulacic N (2016) Surgical regenerative treatments for peri-implantitis: meta-analysis of recent findings in a systematic literature review. J Oral Maxillofac Res.; 7: e15. 14. Khoshkam V, Del Amo FSL, Monje A, Lin GH, Chan HL, Wang HL (2016) Longterm radiographic and clinical outcomes of regenerative approach for treating Peri-implantitis: a systematic review and meta-analysis. Int $\mathbf{J}$ Oral Maxillofac Implants;31: 1303-1310.

15. Bartold PM, Gronthos S, Ivanovski S, Fisher A, Hutmacher DW (2016). Tissue engineered periodontal products. J Periodontal Res. 51(1):1-15.

16. Henkel, K.O., Gerber, T., Lenz, S., Gundlach, K.K.H. \& Bienengraeber, V (2006) Macroscopical, histological, and morphometric studies of porous bone-replacement materials in minipigs 8 months after implantation. Oral Surgery Oral Medicine Oral Pathology Oral Radiology and Endontology 102: 606-613.

17. Punke, C., Zehlicke, T., Boltze, C. \& Pau, H.W (2008) Experimental studies on a new highly porous hydroxyapatite matrix for obliterating open mastoid cavities. Otology \& Neurotology 29: 807-811.

18. Punke, C., Zehlicke, T., Boltze, C. \& Pau, H.W (2009) Investigation of a new highly porous hydroxyapatite matrix for obliterating open mastoid cavities - application in guinea pigs bulla. Laryngo-Rhino-Otologie 88: 241- 246.
19. Liu, Q., Douglas, T., Zamponi, C., Becker, S.T., Sherry, E., Sivananthan, S., Warnke, F., Wiltfang, J. \& Warnke, P.H. (2011) Comparison of in vitro biocompatibility of NanoBone((R)) and BioOss((R)) for human osteoblasts. Clinical Oral Implants Research 22: 1259- 1264.

20. Ghanaati, S., Barbeck, M., Willershausen, I., Thimm, B., Stuebinger, S., Korzinskas, T., Obreja, K., Landes, C., Kirkpatrick, C.J. \& Sader, R.A (2013a) Nanocrystalline hydroxyapatite bone substitute leads to sufficient bone tissue formation already after 3 months: Histological and histomorphometrical analysis 3 and 6 months following human sinus cavity augmentation. Clinical Implant Dentistry and Related Research 15: 883-892.

21. Ghanaati, S., Udeabor, S.E., Barbeck, M., Willershausen, I., Kuenzel, O., Sader, R.A. \& Kirkpatrick, C.J (2013b) Implantation of silicon dioxide-based nanocrystalline hydroxyapatite and pure phase betatricalciumphosphatebone substitute granules in caprine muscle tissue does not induce new bone formation. Head \& Face Medicine 9: 1.

22. Heinemann, F., Mundt, T., Biffar, R., Gedrange, T. \& Goetz, W (2009) A 3-year clinical and radiographic study of implants placed simultaneously with maxillary sinus floor augmentations using a new nanocrystalline hydroxyapatite. Journal of Physiology and Pharmacology 60(Suppl. 8): 91- 97.

23. Kruse, A., Jung, R.E., et.al, (2011) Bone regeneration in the presence of senthetic hydroxyapatite/silica oxide based and xenogenic hydroxyapatite based bone substitute material. Clinical Oral Implants Research 22: 506- 511.

24. Shakibaie, M.B (2013) Comparison of the effectiveness of two different bone substitute materials for socket preservation after tooth extraction: A controlled clinical study. The International Journal of Periodontics \& Restorative Dentistry 33: 223-228.

25. Moller, B., Acil, Y., Birkenfeld, F., Behrens, E., Terheyden, H. \& Wiltfang, J (2014) Highly porous hydroxyapatite with and without local harvested bone in sinus floor augmentation: A histometric study in pigs. Clinical Oral Implants Research 25: 871- 878.

26. Horiuchi N, Maeda T (2006) Statins and bone metabolism. Oral Dis. 12:85-101.

27. Mo H, Yeganehjoo H, Shah A, Mo WK, SoelaimanIN, Shen C-L (2012) Mevalonate-suppressivedietaryisoprenoids forbonehealth.J NutrBiochem.;23:1543-51. 
28. Mundy, G., Garrett, R., Harris, S. , Chan, J. , Chen, D. , Rossini, G. , Boyce, B. , Zhao, M. , Gutierrez, G (1999) Stimulation of bone formation in vitro and in rodents by statins. Science 286, 1946-1949.

29. Ho, M.L., Chen, Y.H., Liao, H.J., Chen, C.H., Hung, S.H., Lee, M.J., Fu, Y.C., Wang, Y.H., Wang, G.J., Chang, J.K. (2009) Simvastatin increases osteoblasts and osteogenic proteins in ovariectomized rats. Eur. J. Clin. Invest. 39, 296-303

30. Stein D, Lee Y, Schmid MJ, Killpack B, GenrichMA, Narayana N, et al (2005) Local simvastatin effects on mandibular bone growth and inflammation. J Periodontol. 76:1861-70.

31. Nyan M, Sato D, Oda M, et.al (2007) Bone formation with the combination of simvastatin and calcium sulphate in critical sized rate calvarial defect. JPharmacolSci.;104:384-6.

32. Goes P, Lima NA, Rodrigues JAG, Benevides NMB, Brito GAC, Lima V (2016) Anti-inflammatory and antiresorptive effects of atorvastatin on alveolar bone loss in Wistar rats. Braz Dent J Brazil 27:267-272

33. Fang, W. ,Zhao, S. ,He, F. ,Liu, L., Yang, G (2015) Influence of simvastatin-loaded implants on osseointegration in an ovariectomized animal model. BioMed Res. Int 831504 DOI: $10.1155 / 2015 / 831504$

34. Sanz M, Chapple IL. (2012) Clinical research on periimplant diseases: consensus report of working group 4. J Clin Periodontol.;39(Suppl. 12): 202-206.

35. Silness J, Löe H. (1964) Periodontal disease in pregnancy II. Correlation between oral hygiene and periodontal condition. Acta Odontol Scand.;22:121-135.

36. Mombelli, A., van Oosten, M. A., Schurch, E. Jr, \& Land, N. P. (1987) The microbiota associated with successful or failing osseointegrated titanium implants. Oral Microbiology and Immunology, 2(4), 145-151. https :// doi.org/10.1111/j.1399-302X.1987.tb002 98.X

37. Arthur B, Umberto D, Mariana d, Gabriel B:New strategies and developments for peri-implant disease. Braz. Oral Res. 2019;33(suppl):e071.

38. Persson Leif G, Tord Berglundh Lars Sennerby Jan Lindhe:Re-osseointegration after treatment of periimplantitis at different implant surfaces. An experimental study in the dog. Clin. Oral Impl. Res. 12, 2001 / 595-603.

39. Meenakshi S, Raghunath N1, Anil Kumar Gujjari: Implant hygiene and soft tissue management: Dentist's perspective.
International Journal of Health \& Allied Sciences. Jul-Sep 2013.

40. Meyer U, Wiesmann HP, Neunzehn J, Joos U. Bone tissue engineering. In: Ferri J, Hunziker EB, editors. Preprosthetic and maxillofacial surgery. 1st ed. Cambridge (UK): Woodhead Publishing Limited; 2011. p. 1-24.

41. Roccuzzo M, Savoini M, Dalmasso P, et.al (2017) Long term outcomes of implants placed after vertical alveolar ridge augmentation in partially edentulous patients: A 10 years postoperative clinical study. Clin Oral Implants Res: 28:1204/1210.

42. Gerike W. Bienengräber V. Henkel K. et al (2006) The manufacture of synthetic non-sintered and degradable bone grafting substitutes. Folia Morphol (Warsz) 65:54-55.

43. Bauer, T.W. \& Muschler, G.F. (2000) Bone graft materials. An overview of the basic science. Clinical Orthopedics and Related Research 371: 10- 27.

44. Baigent, C., Keech, A., Kearney PM (2005): Efficacy and safety of cholesterol-lowering treatment: prospectivemetaanalysis of data from 90056 participantsin 14 randomisedtrials of statins. Lancet. 366: 1267-78.

45. Jonathan Meza-Mauricio1 \& David Soto-Peñaloza2 \& David Peñarrocha-Oltra2 \& Jose Maria Montiel-Company2 \& Daiane Cristina Peruzzo (2018) Locally applied statins as adjuvants to non-surgical periodontal treatment for chronic periodontitis: a systematic review and meta-analysis. Clinical Oral Investigations 22:2413-2430.

46. Zitzmann NU, Berglundh $\mathrm{T}$ (2008) Definition and prevalence of peri-implant diseases. J Clin Periodontol.; 35: 286-291.

47. Schwarz, F., John, G., Schmucker, A., Sahm, N., \& Becker, J (2017) Combined surgical therapy of advanced peri-implantitis evaluating two methods of surface decontamination: A 7-year follow-up observation. Journal of Clinical Periodontology, 44(3), 337-342. https:// doi.org/10.1111/ jcpe. 12648 .

48. Devlin, H. \& Yuan, J. (2013) Object position and image magnification in dental panoramic radiography: a theoretical analysis. Dentomaxillo- facial Radiology 42: 29951683. doi:10.1259/dmfr/ 29951683.

49. Elisabetta Polizzi, Bianca Dorto,Simone Tomasi, Giulia Tetè:A micromorphological/microbiological pilot study assessing three methods for the maintenance of the implant patient. Clin Exp Dent Res. 2020;1-7. 
50. Ritter, L., Elger, M. C., Rothamel, D., Fienitz, T., Zinser, M., Schwarz, F., \& Zoller, J. E. (2014). Accuracy of periimplant bone evalua- tion using cone beam CT, digital intra-oral radiographs and histology. Dentomaxillofacial Radiology, 43(6), 20130088.

51. Stefane R, Hideaki H, Loannis P et.al. The impact of maintenance on peri-implant healthBraz. oral res. vol.33 supl.1 São Paulo 2019 Epub Sep 30, 2019.

52. Schwarz, F., Sahm, N., Bieling, K., et.al (2009) Surgical regenerative treatment of peri-implantitis lesions using a nanocrystalline hydroxyapatite or a natural bone mineral in combination with a collagen membrane, A four-year clinical follow-up report. Journal of Clinical Periodontology, 36(9), 807-814.

53. Roccuzzo, M., Gaudioso, L., Lungo, M., \& Dalmasso, P (2016) Surgical therapy of single peri-implantitis intrabony defects, by means of deproteinized bovine bone mineral with $10 \%$ collagen. Journal of Clinical Periodontology, 43(3), 311-318. https://doi.org/10.1111/ jcpe.12516

54. Sakoda K, Yamamoto M, Negishi Y, Liao JK, Node K, Izumi Y (2016) Simvastatindecreases IL-6 and IL-8production inepithelialcells. J Dent Res [Internet]. 2006; 85:520-3. Available from:

55. Ting M, Whitaker EJ, Albandar JM. Systematic review of the in vitro effects of statins on oral and perioral microorganisms. Eur J Oral Sci [Internet].;124:4-10.

56. Suresh S, Narayana S, Jayakumar P, Sudhakar U, Pramod V. Evaluation of anti-inflammatory effect of statins in chronicperiodontitis (2013) IndianJ Pharmacol;45:391-4.

57. CicekAriV, Ilarslan YD, Erman B, et.al (2016) Statins and IL-1 $\beta$, IL-10, and MPO levels in gingival crevicular fluid: preliminary results.Inflammation. 39:1547-57. 